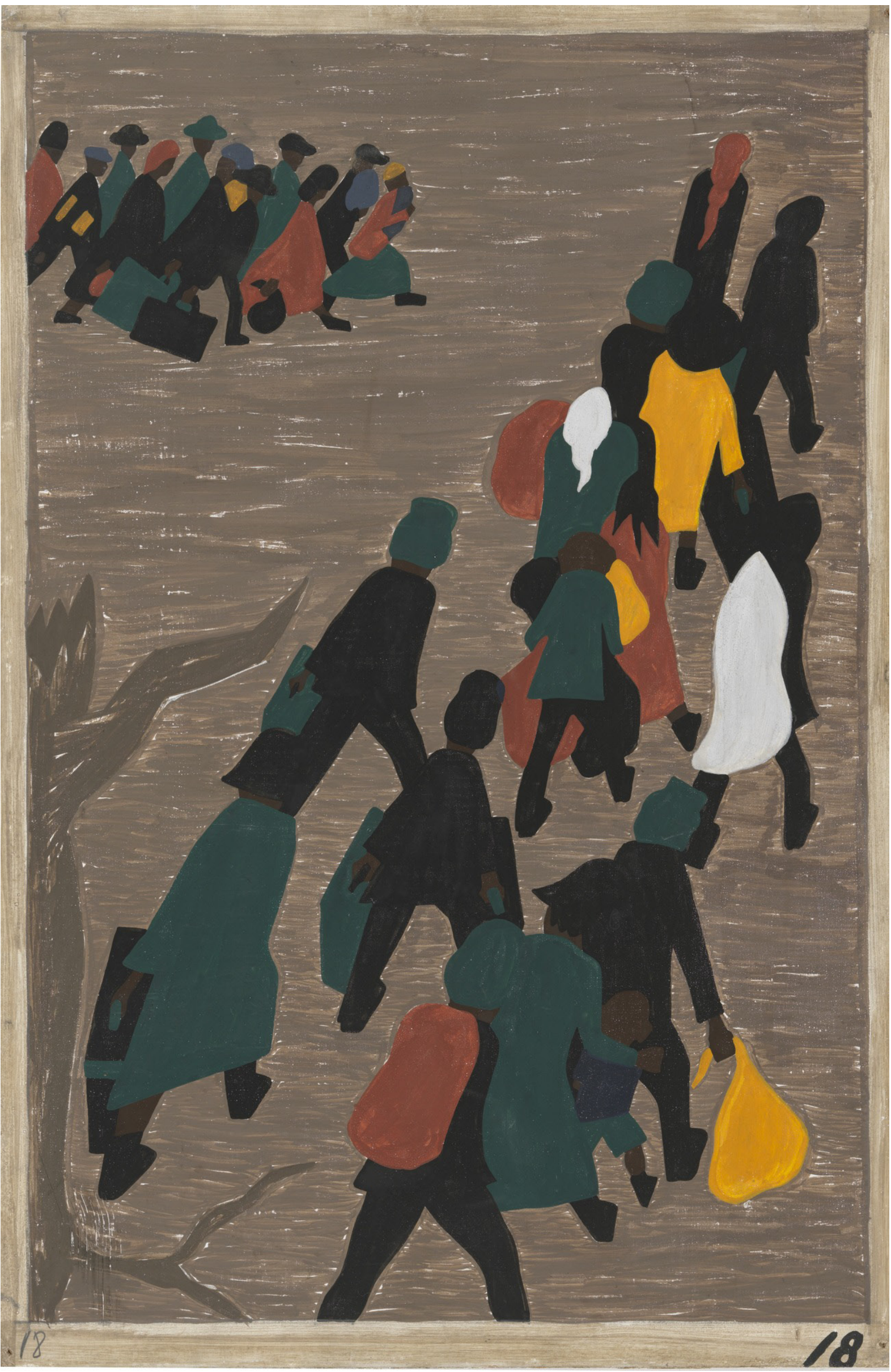




\title{
AFINAL, QUEM É MIGRANTE?
}

\section{Agência e historicidade na mensuração da migração internacional recente no Brasil}

\author{
MARDEN BARBOSA DE CAMPOS*
}

RESUMO O presente ensaio discute a agência e historicidade das estatísticas sobre migração internacional produzidas no Brasil. Seu argumento central é que o momento histórico atual cria agenciamentos específicos formados por uma articulação entre órgãos governamentais, universidades e centros de pesquisa na sustentação do conceito de migrante. Para isso, apresenta as bases conceituais sobre as quais são feitas as tentativas de mensuração da migração, como foco nos dados censitários sobre o fenômeno. Termina destacando como novas fontes de informação e ferramentas de análise que surgem com o avanço das tecnologias de comunicação e deslocamento nos forçam a repensar, conceitualmente, as categorias de análise que normalmente utilizamos para estudos quantitativos sobre o tema.

Palavras-Chave Migração. Fontes de informação. Brasil.

\section{WHO IS A MIGRANT, AFTER ALL? Agency and historicity in the measurement of the recent international migration in Brazil.}

ABSTRACT This essay discusses the agency and historicity of statistics on international migration produced in Brazil. Its main argument is that the current historical moment creates specific assemblages, formed by an articulation among governmental agencies, universities and research centers in support of the concept of migrant. Therefore it presents the conceptual bases on which attempts are made to measure migration with the focus on census data on migration. It finishes highlighting how the new sources of information that emerge with the advancement of communication and displacement technologies force us to rethink, conceptually, the categories of analysis that we normally use for quantitative studies on the subject.

KEYwORDs Migration. Data sources. Brazil.

*Professor da Fafich/UFMG. E-mail: mardencampos@gmail.com 


\section{Introdução}

1 racionalidade é um dos enredamentos que unem as ciências modernas e os produção de estatísticas "oficiais", "confiáveis" e "relevantes” são uma das formas de sustentação de sua continuidade e existência. Vista sob essa perspectiva, a produção de estatísticas sobre eventos sociais - nos quais se inclui a migração - sustentar-se-ia sobre discursos legitimadores com raízes tanto no campo governamental (o Estado) quanto acadêmico disciplinar, escancarando o acordo (político) implícito entre esses campos.

O presente ensaio busca discutir a agência e historicidade das estatísticas sobre migração internacional produzidas nas últimas décadas no Brasil, dando destaque para o enredamento de conceitos e processos de produção de estatísticas sobre o tema. Especificamente, discute a forma como "a modernidade" constrói migrantes, imobiliza movimentos, com foco na principal fonte de informação utilizada para estudo das migrações na atualidade: os censos demográficos e seu instant décisif de uma população.

O argumento central do texto é que o momento histórico atual, em que vigora a busca por objetividade e racionalidade típica das formas de ver o mundo, cria agenciamentos específicos, formados por uma articulação entre órgãos governamentais, universidades e centros de pesquisa na sustentação do conceito de migrante. Contudo, uma análise demorada desses processos nos mostra que, ao mesmo tempo que haveria uma "solidificação" conceitual/operacional dos processos de produção dessas estatísticas, haveria, por outro lado, uma "liquefação" das formas de mobilidade espacial da população que põe à prova todo o aparato moderno de produção de informação.

Em caráter ensaístico, o texto dialoga com perspectivas que discutem como a construção de informações sobre uma realidade participa da construção da própria realidade que se propõe a medir, por carregarem, antes de irem a campo, formas de ver e de pensar o mundo. Expõe, assim, os discursos legitimadores da informação, com base nas questões ideativas e problemas práticos da construção de informações sobre migra- 
ção, destacando as disciplinas autorizadas a falar com base nessas informações. Mostra também as lacunas deixadas por esse processo, envoltas em discursos “alternativos” ou “não oficiais" que, ao forçarem a fronteira conceitual, desembocam em falas xenofóbicas, raramente dando voz ao principal objeto da análise, os próprios migrantes.

Para isso, apresenta as bases conceituais sobre as quais são feitas as tentativas de mensuração da migração, partindo de distinções e critérios temporais e espaciais que irão definir o conceito de migrante e os deslocamentos espaciais “duradouros" e “distantes". Também é feita uma problematização dos processos de coleta utilizados nos censos demográficos, as entrevistas, os caminhos percorridos pela informação, os instrumentos de armazenamento, processamento e divulgação dos dados.

Acredita-se que vivemos um momento histórico, na virada do milênio, que nos força a repensar a forma como construímos (informações sobre) a realidade em que vivemos. E as novas mobilidades, as novas fontes de informação e as novas ferramentas de análise que surgem com o avanço das tecnologias de comunicação e deslocamento nos dão farto material para discutir essa questão.

\section{Desafios}

O estudo dos fenômenos sociais muitas vezes esbarra nas dificuldades de dimensionar a magnitude dos eventos. Entre outros aspectos, isso decorre da falta de reflexão constante sobre os processos de produção, o que é amplificado ainda mais quando se considera que a produção de informação sobre a realidade influencia (gera reflexo) essa mesma realidade - modernidade reflexiva.

Embora seja um fenômeno comum entre as populações humanas, a migração está correntemente sujeita a mudança de significado e importância, dependendo da maneira como se insere em cada contexto histórico. Ganha contornos específicos em cada lugar e momento, o que influencia, consequentemente, na sua conceituação e possibilidade de mensuração.

Os desafios para estimação da direção, composição e volume dos fluxos populacionais decorrem de diversos fatores, entre os quais se destacam a volatilidade dos fluxos migratórios, fortemente correlacionados a aspectos conjunturais - como conflitos internos, ciclos econômicos e contextos políticos locais - além da ausência de 
amparo legal ou documental com que vivem muitos migrantes nos países de destino. Em acréscimo, uma questão importante impõe uma tarefa extra para o cálculo dos volumes da migração: a definição de migrante e suas diferenças com relação a outras formas de mobilidade espacial. As tensões conceituais relacionadas ao trinômio moradia-deslocamento-migração definem quem deverá ou não ser considerado migrante em cada processo de mensuração e quem deve ser "estatisticamente invisibilizado" por cada um deles.

Nossa inspiração principal é o trabalho de Alain Desrosières, no qual o autor discute a política dos grandes números e defende que os dados estatísticos devem ser sempre discutíveis, não apenas quanto à sua fidelidade ou seriedade, mas também no que se refere à problematização de seu processo de produção (DESROSIÉRES, 2004). Segundo o autor, os números são importantes na vida social não tanto pelo que dizem, mas pelo fato de que a sociedade concorda em discutir com base neles. O importante não é apenas que os números sejam confiáveis, mas que os encaremos - e tenhamos elementos que nos levem a creditá-los - como confiáveis. Isso envolve desde a alfabetização da população (ou parte dela), da disseminação de uma lógica de pensamento científico, de instituições confiáveis, processos de produção razoavelmente transparentes e, em última instância, de Estados legítimos. Os números são a linguagem da modernidade e, por isso, tornam-se a sustentação de argumentos que são, ao mesmo tempo, científicos e políticos.

Para os propósitos que interessam ao presente ensaio, é importante procurar rastrear, com base na discussão que viemos travando, quais caminhos as informações e estatísticas percorrem, quais os agentes envolvidos em sua produção e quais as perguntas legitimadoras dos processos produtivos. Isso nos daria segurança de que a informação se refere a algum evento cuja manifestação foi “capturada” por uma operação de coleta, muito mais do que apenas afirmar, sem nenhum tipo de reflexão, que o dado é "oficial".

A discussão das informações provenientes dos censos demográficos encontra-se no meio dessa encruzilhada. Eles são tomados, nos estados modernos, como a fonte de informações mais importante na formulação de políticas estatais e de estudos sociais. Ao mesmo tempo, os censos são atores importantes na construção da própria realidade a que se propõe investigar, dando inclusive sustentação à existência dos Estados atuais (ANDERSON, I99I). 
Como, na modernidade, vivemos cada vez mais “mergulhados” em uma cultura estatística, nós nos habituamos a enxergar a sociedade por meio de gráficos e tabelas, de curvas e percentuais, sem considerar que esses artefatos são construções recentes que obscurecem muitos aspectos experimentados pelos indivíduos (IGO, 2008).

A próxima seção busca discutir essa complexidade e sua utilidade para os estudos da migração.

\section{Inspirações}

A questão do papel das estatísticas na apreensão da realidade moderna é destacada de forma diferente em quatro trabalhos que foram selecionados como contrapontos à presente discussão.

O trabalho de Alan Desrosières (2004), cuja discussão iniciamos na seção anterior, será apresentado com mais detalhes. O autor propõe-se a discutir o que para ele tem sido "objeto indiscutível" na estatística: como os conceitos e medidas utilizados pelos cientistas para mensurar a realidade interferem na construção do objeto mensurado e como a história desses conceitos e medidas interfere na construção dessa realidade. Ao realizar uma história das medidas estatísticas, o autor remonta à fundação das ciências sociais modernas e aos conflitos do uso das ferramentas estatísticas então criadas para as análises sociais. Ele leva a questão até o nascimento das ciências sociais modernas, quando dialoga com a máxima durkheimiana de que "os fatos sociais devem ser tratados como coisas. Segundo Desrosières, esse tipo de abordagem metodológica, mais do que "descobrir" uma regularidade nos fatos sociais, questiona se há utilidade e rendimento analítico em nos forçarmos a ver esses fatos como se fossem coisas.

Afora os debates entre realismo e idealismo, fato é que, com a consolidação dessa perspectiva, os fatos sociais tornaram-se coisas. Nesse sentido, Desrosières mostra que as medidas estatísticas são entes novos, frutos de convenções e arranjos institucionais que formam o corpo das ciências modernas. Dependem, por isso, de uma rede de significados institucionalmente estabelecidos. Ao usarmos medidas estatísticas, recebemos os conceitos prontos, encapsulados, compactos em formulações concisas, sem perceber que essas ferramentas foram produto de uma gestação histórica repleta de dúvidas, traduções e conflitos de interpretação. 
É importante enfatizar, para o tipo de análise que se faz neste artigo, que Desrosières foge sempre da tensão idealismo/realismo, traduzida no fato de a estatística descobrir ou criar seus objetos de estudo. O autor enfatiza seguidas vezes que o que ele busca é transitar por uma argumentação intermediária em que a estatística, ao mesmo tempo que descobre coisas novas, atua na criação dessas mesmas coisas. Isso é importante, pois rearticula o sujeito e o objeto da pesquisa por meio do instrumento de investigação, mostrando como essas “entidades" participam de uma totalidade maior, em permanente construção.

Em suma, se apostarmos com Desrosières que os fatos sociais dependem, ainda que parcialmente, de determinados tipos de construções formais, podemos pensar que outros tipos de medidas criariam outros tipos de fatos sociais. Nesse sentido, percebemos que, ao destacarmos certos aspectos (mas não todos) da "realidade", aos quais atribuímos caráter de verdade, deixamos de perceber outras facetas dessa mesma realidade, que se tornam invisíveis e, por isso, inexistentes.

O trabalho de Porter (I995) dedica-se à descrição do processo de busca pela objetividade que foi feito tanto por cientistas como por políticos e cidadãos comuns nos últimos séculos, com o intuito de construir “conhecimento legítimo” sobre os fenômenos sociais. Segundo ele, o aspecto mais importante na busca pela objetividade e, consequentemente, na “fé" que depositamos nos números, advém de sua capacidade de gerar consenso. Ou seja, a objetividade seria uma arma contra a distância e a descrença. Os processos de quantificação são vistos pelo autor como uma tecnologia social na busca pelo consenso. O autor cita os números, gráficos e fórmulas, acima de tudo, como estratégias de comunicação e padronização dos discursos. Legitimam, nesse sentido, o pertencimento a uma comunidade. Para Porter, o ponto central é que a quantificação é uma “tecnologia de distância”, sendo a matemática o elemento mais importante do processo.

A tônica por trás dos números é que, sendo apresentados como sinônimo de rigor, dado que as regras para coletar e manipular os números são compartilhadas amplamente, os discursos matemáticos e estatísticos, altamente disciplinados, ajudariam a produzir formas de conhecimento que independem das pessoas que as produzem. Logo, o autor ancora seu argumento na noção weberiana de racionalidade, em que a fuga da subjetividade e a busca de impessoalidade seriam a marca da ciência moderna. A confiança nos números e na manipulação quantitativa minimizam a necessidade 
de conhecimento íntimo e da confiança pessoal, não dependendo assim das opiniões pessoais dos indivíduos.

A única crítica ao processo de quantificação excessiva feita pelo autor é o fato de que ele nos leva a basearmos em aspectos superficiais, perpassando fatos de maior profundidade. A fuga da subjetividade e dos aspectos não mensuráveis do processo de pesquisa social acaba deixando de capturar aspectos de extrema importância e difícil percepção, cuja falta empobrece significativamente os resultados quantitativos, simplificando exageradamente os fenômenos estudados.

O que o autor se esquece, e que poderia ser retirado também das ideias de Max Weber sobre a racionalização e modernização dos consensos sociais, é que essa forma de ver o mundo é particular das sociedades modernas, e sua expansão em âmbito mundial se deu em razão da imposição do modo de ver o mundo dessas sociedades, na forma de uma ontologia estatística, temas amplamente tratados por Michel Foucault (I975; I979). No lugar da pretensa despolitização da informação, o império da objetividade carrega forte conotação modernizante e, por isso, é de cunho político.

Essa questão fica clara no texto clássico de Benedict Anderson, Comunidades Imaginadas (ANDERSON, 200I). Nele, esse autor mostra que a criação dos Estados Modernos e o desenvolvimento do nacionalismo emanam de um novo tipo de organização que surge na era moderna, em que as pessoas passaram a se sentir parte de uma comunidade que extrapola a sua rede de contatos. Surge para as pessoas uma ideia de pertencimento a uma comunidade de indivíduos com os quais, em sua maioria, elas nunca vão se encontrar, mas que se "imaginam” conjuntamente pertencendo a um mesmo coletivo. Nesse sentido, a Nação seria uma comunidade política “imaginada”, uma vez que nunca poderia ser "experimentada”.

Entre os processos que trabalham na construção desse tipo de comunidade, o autor destaca o papel de três instituições de poder, de onde emanaria a gramática desse imaginário: o mapa, o museu e o censo. Segundo Anderson, essas instituições mudaram em termos de forma e de função na modernidade e moldaram a maneira como o Estado imaginava sua soberania, em termos da natureza dos seres que governava, da geografia de seu território e da legitimidade de sua ancestralidade.

O censo mostra quem e como são os cidadãos para os quais o Estado governa. Dificilmente determinados grupos sociais teriam reconhecido a si mesmos como per- 
tencendo à mesma comunidade, da forma como os censos mostram e aglutinam. As identidades (confusamente) imaginadas na mente classificadora do Estado sofrem constante reificação com o uso de censos.

Segundo Anderson, nota-se uma paixão pela exaustividade e pela ausência de ambiguidade por parte daqueles que concebem o censo, geralmente intolerantes a classificações múltiplas, vagas ou em mutação. Segundo o autor, a ficção do censo é a de que ele integra toda a gente e de que toda a gente teria um - e apenas um - lugar extremamente bem definido na sociedade. Ao criar categorias, o censo homogeniza diferenças e torna "iguais" aqueles que, de outra forma, seriam "diferentes”. Cabendo no questionário do censo, o indivíduo pertence à nação. De outro modo, não.

No texto de Sarah Igo (2008), a ideia central é que, na modernidade, vivemos mergulhados em uma "cultura estatística". Com base na análise do papel das pesquisas sociais na sociedade americana, a autora mostra como habituamos a enxergar a sociedade por meio de gráficos e tabelas, de curvas e percentuais. Igo destaca que as pesquisas sociais deixaram de ser direcionadas apenas para o estudo dos considerados pobres, degenerados, problemáticos, delinquentes ou defeituosos, como ocorria no século XIX, incorporando cada vez mais padrões de população considerada "normal" ou "típica". Remetendo a Hannah Arendt, a autora demostra que o "social” foi uma invenção do século XIX, na medida em que determinados tipos de problemas passaram a fazer parte do terreno político de criação das nações. Coisas que antes eram vistas como pontuais ou localizadas passaram a ser transformadas em categorias sociais, compartilhadas por grupos mais amplos de indivíduos, principalmente entre os membros de uma mesma nação. Desse modo, o pobre, o mendigo ou o alcoólatra, antes apenas imediatamente percebidos nas redondezas, transformam-se em “pobreza”, em “nível de miséria” e em “taxas de alcoolismo". Passam a ser problemas de “todos”. Transformam-se os infortúnios individuais repreensíveis em condições sociais de responsabilidade coletiva.

Uma vez que essas categorias são criadas e começam a ser aceitas, elas solidificamse com o tempo. De todo modo, no momento em que passamos a enxergar e pertencer a um coletivo maior, enxergamos não só o estatisticamente problemático e desviante como também um coletivo “normal', “típico" ou "médio", que muitas vezes se encontra distante de nosso convívio imediato. Chega-se assim ao ponto central da análise de Igo: a construção numérico-estatística de uma “média” na sociedade. 
Pelo fato de, aparentemente, não transparecerem opiniões ou interpretações, mas “apenas os fatos”, aos dados estatísticos é conferida autoridade pela neutralidade. Nesse sentido, cria-se uma espécie de fetiche pelos números e, consequentemente, pelos processos sociais que os produzem, tornando invisíveis todas as articulações e embates implícitos ou ocultos.

\section{Os conceitos e o aprisionamento dos migrantes}

O deslocamento espacial de um indivíduo envolve ações extremamente simples e triviais como os atos de andar, dançar ou "sair para correr", como nos lembra bem Cresswell (2006). Em meio a diversas formas de mobilidade espacial, a migração ocupa um ponto especial, tendo todo um campo de estudos a ela dedicado. Isso se dá em razão de tratar-se de uma forma de mobilidade considerada "duradoura" ou "permanente", que provoca impactos diversos nas populações envolvidas.

Embora, conceitualmente, seja fácil aceitar as afirmações anteriores, não é simples delimitar a fronteira que separa a migração de outras formas de mobilidade espacial, justamente pela necessidade, muitas vezes arbitrária, em definir quais deslocamentos serão definitivos e quais deles temporários.

De todo modo, a busca pela precisão desses conceitos e pela objetividade das medidas estatísticas é uma obsessão do mundo moderno. Há mais de um século já se publicavam estudos que buscavam o mesmo tipo de rigor que hoje tentamos aplicar às estatísticas de migração (ver, por exemplo, RAVEINSTEIN, I889).

Os dados sobre migração podem referir-se tanto ao ato de migrar propriamente dito - a migração - como ao indivíduo que realiza essa ação - o migrante. Embora em termos conceituais constantemente façamos referência ao termo "migração", na prática, a maior parte das informações quantitativas de que dispomos hoje em dia referese aos migrantes. Enquanto o primeiro tipo de medida, referente ao ato de migrar, é considerado um dado de fluxo, a informação sobre os migrantes sempre será um dado de estoque. Em termos práticos ou "de campo", a migração (fluxo) é sempre definida $a$ posteriori, após a captação de um migrante (estoque) que tenha sobrevivido até o momento da entrevista ou registro, tanto à morte como à reemigração.

Há ainda abordagens que consideram uma dimensão espacial mais ampla, como "espaços de vida" (COURGEAU, I988), próximas de uma ideia de habitat. Nesse tipo 
de medida, que impõe sérias dificuldades operacionais para levantamentos de larga escala, busca-se desenhar todos os locais por onde os indivíduos deslocam-se ao longo de períodos pré-determinados pelo pesquisador.

A definição de migração que embasa as estatísticas sobre o tema envolve critérios temporais e espaciais. Primeiramente, pelo critério espacial, pode-se afirmar que a migração sempre supõe que houve um deslocamento espacial. Qual seria a distância mínima a ser percorrida para ser considerado migração? O segundo - e também fundamental - critério para definir a migração é de ordem temporal. Qual o tempo mínimo que se deveria permanecer em um local para ser considerado migrante? Esse critério é o que normalmente carrega o maior nível de arbitrariedade.

Conforme destacado, a migração seria então representada, conceitualmente, por um deslocamento espacial "duradouro" e "distante”. Em termos operacionais, contudo, torna-se difícil implementar esses conceitos. Pelo lado da distância, normalmente utiliza-se uma mudança de área como referência espacial, enquanto para a questão da permanência é considerada a intencionalidade do deslocamento. Deve-se destacar que essas áreas não são definidas pelos pesquisadores, mas, sim, adotadas por eles. O fato de municípios, estados e países serem ou não áreas aceitáveis para se definir migração é algo que precisa ser discutido e determinado. Caso concordemos com a definição, o migrante será definido, pela ótica espacial, sempre que cruzar uma fronteira político-administrativa.

Pelo lado temporal, pode-se utilizar o tempo de residência (passado ou planejado) na localidade ou, como no caso dos censos brasileiros, utilizar-se o critério residencial em substituição ao tempo de residência. Nesse caso, considera-se migrante aquele que mudou definitivamente de residência entre localidades distintas independentemente do tempo em que se deu essa mudança. Pois é justamente no momento em que se necessita realizar uma operacionalização dos conceitos que desponta a questão da agência na produção das informações sobre migração, na medida em que um órgão oficial, geralmente parte do aparelho estatal, legitima-se conceitualmente pela necessidade de "resolver" problemas práticos, ainda que criados pelos mesmos processos que tentam captar.

Visto sob essa perspectiva, o processo carrega tamanha arbitrariedade que não sabemos se estamos criando ou descobrindo uma "realidade" que se manifesta externamente ao processo de captação.

Outro fator que amplia o problema da diferenciação entre migração e outras formas de mobilidade espacial para os estudos de migração internacional é o fato de a pró- 
pria definição de migrante, mesmo de acordo sobre os critérios tempo-espaciais, ainda ser ambígua. Se pensarmos em termos demográficos, focando a contribuição da migração para a variação do tamanho de uma população, o migrante será todo indivíduo que entrou ou saiu definitivamente da população em determinado período de tempo, independentemente de seu local de nascimento. Ou seja, os naturais de um local que dele saem e posteriormente a ele retornam também devem ser contabilizados entre os migrantes. Nesse sentido, serão considerados como imigrantes todos os brasileiros que retornam ao Brasil após um período de residência no exterior.

Por outro lado, o termo migrante, pensado como sinônimo da palavra "estrangeiro", levou à criação da categoria "migrante de segunda geração", referente aos filhos dos estrangeiros nascidos no país de destino que, em grande parte, nunca migraram.

\section{Os processos de coleta ou os caminhos dos conceitos}

No momento em que novas fontes de informação são trazidas para o centro da criação de conhecimento, somos forçados a fazer uma reflexão sobre o nosso processo de construção dessas informações. Nesse sentido, é necessário investigar qual o potencial explicativo de cada fonte, quais as interseções entre as diferentes bases de dados e quais facetas do fenômeno são ou não cobertas pelo conjunto de dados atualmente disponíveis. Nesta seção, será realizado um “mergulho” no processo de construção dos dados quantitativos sobre migração, tomando como exemplo os censos demográficos, na tentativa de explicitar a natureza processual e histórica desse tipo de informação.

Segundo Latour (200I), a negligência em conhecer as etapas intermediárias da construção da informação provoca um grande salto (o "salto mortale") entre a realidade que se quer retratar e a informação construída sobre ela, criando uma descontinuidade intransponível entre esses dois extremos. É certo que, mesmo separando o processo em etapas, ainda haverá uma descontinuidade entre elas. Contudo, segundo o autor, será mais fácil passar pequenas “pontes” entre essas etapas do que saltar uma "grande ponte" que buscasse articular a informação e a "realidade" à qual ela se refere. Alinhavando as etapas que mediam esse processo, podemos transitar (transladar) facilmente entre elas, indo de um ponto (os dados) ao outro (a realidade) sem trancos ou saltos 
bruscos. Isso acrescentaria ainda mais "realidade” à informação, na medida em que ela poderia circular suavemente entre as etapas de pesquisa, por meio de mecanismos conhecidos e bem definidos, dando-nos garantia de que se refere a um fenômeno cuja existência escapa, em algum grau, do processo de captação.

No Brasil, a informação censitária é baseada em entrevistas domiciliares, fruto de um processo que começa com o mapeamento e contagem de domicílios, cuja definição ancora-se em conceitos bem definidos. Esses domicílios serão visitados por recenseadores que, após um período de treinamento, entrevistarão os indivíduos que forem considerados moradores do domicílio (e do país) segundo critérios rígidos. Cumpridos os critérios que qualificam o domicílio de residência e a condição de morador, o entrevistado será inquirido sobre seu local de nascimento, local de residência anterior, tempo de residência no país, na Unidade da Federação e no Município, assim como local de residência cinco anos antes do censo. Durante o processo da entrevista, a informação será registrada em um dispositivo de armazenamento, submetida a processos de crítica e correção para, em seguida, ser agrupada em bases de dados que, enfim, serão divulgadas em meio impresso ou digital. Os usuários, por sua vez, irão reorganizar as informações em tabelas e quadros, com base nos conhecimentos que adquiriram em seu processo de formação, utilizando de sua capacidade de manipulação de softwares, pacotes estatísticos e planilhas digitais, assim como de conceitos, teorias e métodos de análise de dados migratórios a que foram expostos previamente. Esses dados serão submetidos, então, à confrontação com teorias, métodos, modelagem estatística e econométrica, serão cruzados entre si e com outras variáveis e comparados "no tempo", ou seja, com censos anteriores e posteriores, além de informações de outras fontes e censos de outros países.

A cada uma dessas etapas, os dados são (re)direcionados, percorrem caminhos, confirmam ou refutam percepções e aproximam-se da realidade do migrante ou da mentalidade do próprio pesquisador.

A comparação "no tempo" exemplifica as imbricações e aspectos complicadores do processo. Por exemplo: apesar de, nos últimos dois censos demográficos, os conceitos tanto de morador, domicílio e migrante - conceitos mínimos que qualquer pesquisador deveria conhecer ao interpretar essas informações - não terem mudado, os instrumentos de coleta foram totalmente remodulados, passando de entrevistas em papel para 
coleta digital (em minicoletores de mão e smartphones). Além de alterar o registro da informação e o trânsito pelo questionário no momento da entrevista, o “caminho" que a informação segue após a coleta é bastante diferente. De um processo de coleta (e conferência) manual, como no Censo Demográfico 2000, a informação, em 20I0, passou a ser, coletada e transmitida eletronicamente, submetida a sistemas de crítica informatizados. Nesse caso, livra-se da crítica manual e das incertezas (e vantagens) que esse processo gera, em nome de uma crítica automatizada, mais homogênea e controlável, embora susceptível a imperfeições de outra ordem. Em suma, embora os conceitos fossem os mesmos, os caminhos percorridos pela informação são ligeiramente alterados e, com isso, sofrem um redirecionamento e uma ressignificação.

Não se quer aqui defender um método ou outro, criticar a desumanização promovida pela informatização ou louvar a eficiência dos processos digitais. O que se quer destacar é que essas mudanças acompanham o modo como a sociedade articula seus processos (políticos e institucionais) de produção da informação em cada momento e que as etapas mediadoras responsáveis por fabricar, ou produzir esses dados provocam uma requalificação da informação. No longo prazo, entretanto, a natureza desse tipo de informação, assim como a de outros tipos de dados, sofre uma transformação significativa.

Contextualizando o processo em termos históricos e espaciais, vemos que, para que uma pesquisa censitária seja realizada em domicílios, é preciso que toda população resida em moradias desse tipo onde o morador possa ser encontrado para a entrevista.

Apesar da obviedade aparente dessa afirmação poder ser motivo para considerála irrelevante, ela representa um ponto extremamente importante no que se refere à captação de migrantes internacionais, como no caso daqueles que estão no país com situação de permanência indefinida.

Todo conhecimento sobre a migração produzido em determinado momento é fruto da articulação entre todas essas etapas, sejam elas políticas, técnicas, analíticas e conceituais. Não só os migrantes mudam, não só as migrações atravessam fases, não só os fluxos alteram sua direção e não só a migração tem uma história, mas também tem uma história o processo de produção de informações e seus instrumentos e instituições envolvidas. E essa é uma história cheia de dúvidas, traduções, conflitos de interpretação e estratégias vitoriosas. 
Os dados dos censos são uma informação tradicional sobre migração, construída com esse único fim e produzida há décadas. Além disso, no Brasil, essa informação é produzida por um instituto que vem, ao longo dos anos, estreitando cada vez mais sua relação com usuários e, já há bastante tempo, conta com a colaboração de especialistas brasileiros e estrangeiros nos processos de pesquisa. Isso faz com que o processo de produção de informação “sofra” escrutínio, seja alvo de críticas e passe por aprimoramentos de forma ininterrupta. Grande parte dos dados de registros administrativos, cada vez mais demandados para análises de migração, ainda não passaram por semelhante processo, embora sejam utilizados cada vez mais como fonte de informação. Por isso, ainda apresentam dificuldades para análise tanto em termos de consistência da informação quanto de dificuldades de acesso.

\section{Os discursos}

Os mecanismos de produção da informação sobre migração estão assentados sobre discursos legitimadores desses processos. Quando falamos de discursos, estamos referindo-nos às construções ideativas que atribuem valor ao que deve e ao que não precisa ser investigado. É preciso prestar atenção à forma como se constroem esses discursos antes de fazer reflexões sobre os fundamentos conceituais do processo. Embora seja impossível abranger a questão discursiva em sua totalidade, alguns pontos merecem destaque. As informações sobre migração no Brasil geralmente são legitimadas em um contínuo que parte de uma extremidade quantificadora, cujas “autoridades" são as disciplinas demografia, economia e geografia, ou da outra extremidade, dominada pela sociologia, história, antropologia e psicologia, em que se dirige a atenção para os impactos da migração nos indivíduos (migrantes ou não), os processos de adaptação e as dificuldades originadas no deslocamento. Enquanto o matiz quantitativo visa saber quantos são os migrantes e onde eles estão, o qualitativo está focado em questões como descentramento, estranhamento cultural e adaptação.

Hoje, no Brasil e em outros países, há predominância de ideais do primeiro tipo legitimando a produção de informações primárias sobre migrações. Os censos demográficos, as pesquisas domiciliares e grande parte dos estudos feitos com base em registros preocupam-se, prioritariamente, em apresentar o volume dos fluxos migratórios, suas variações ao longo do tempo e, principalmente, a direção predominante 
desses fluxos. Isso é o que determina não só sua realização como também seu desenho conceitual e a natureza dos quesitos investigados. Ao mesmo tempo, esse tipo de informação consolida um saber sobre o fenômeno, dado que o conhecimento só é construído com base nesses dados. Isso cria um ciclo que consolida uma disciplina dedicada aos estudos da migração, tanto em termos conceituais como de base empírica. Interessante notar que o foco quantitativo predomina no Brasil mesmo que o volume da migração seja pequeno: o saldo migratório internacional atual do país certamente equivale a menos de I\% da população total.

Há também um discurso construído a respeito da inserção dos migrantes no mercado de trabalho interno e na busca de emprego de brasileiros no exterior. A relação entre migração e trabalho tem ganhado ênfase, principalmente num período em que o Brasil passa a atrair imigrantes e refugiados em busca de trabalho.

Também há um discurso visível, principalmente na imprensa, que se torna perigoso quando importa a fala xenofóbica de alguns países em relação aos imigrantes. Termos como “invasão de estrangeiros" que estariam “tomando empregos" formam opiniões, muitas vezes resultantes da desinformação de profissionais sobre a amplitude e complexidade do fenômeno. Esse modo de pensar, entretanto, ainda não tem fomentado produção de informações sobre migrantes.

Dificilmente temos visto discursos baseados na voz dos migrantes, e são raros os esforços para produzir informação qualitativa sobre o tema em larga escala. O que se começa a perceber, principalmente considerando arranjos construídos para assistência ao migrante, é um discurso focado nas mazelas sofridas por alguns tipos de migrantes (dificuldades de inserção no mercado, violência, tráfico de pessoas, por exemplo) e na necessidade de assistência especial a essas pessoas.

Todos esses pontos destacam a importância de refletir sobre a forma como se interiorizam em nós ideias e preocupações que se transformarão em hábitos metodológicos e estilos de investigação e que serão, ao longo do tempo, consagrados pelas instituições e dispositivos de construção de informações.

O ponto central, novamente, é a (in)definição da fronteira conceitual entre a migração e outras formas de mobilidade e deslocamento espacial. Fica clara, na exposição feita no decorrer do artigo, que a delimitação dessa fronteira restringe a apreensão de um fenômeno cada vez mais importante para a sociedade brasileira: a chegada e a permanên- 
cia de indivíduos nascidos em outros países no território nacional. Embora a definição estrita de migrante possibilite a captação e contabilização de uma parcela significativa dos estrangeiros que estabelecem residência definitiva no país, ela torna invisíveis todos aqueles que não se adaptam à condição de "moradores permanentes" ou "estáveis".

O desafio parte da ideia de que, enquanto muitas pessoas vão entrar e sair do país, algumas delas vão ficar. Resta saber qual seria, então, a relação entre mobilidade e migração, nos tempos em que há uma explosão das formas de comunicação e das possibilidades de deslocamento espacial. Seria essa relação positiva, indicativa de que quanto mais pessoas vão a determinado lugar, maior é o número daquelas que lá permanecem por longo tempo, ou seria uma relação negativa, que mostra que, cada vez mais, é possível ir e voltar sem precisar permanecer no destino? Nesse ponto, é preciso avançar tanto em termos conceituais como empíricos.

Além dos dados de censos, pesquisas e registros de natureza administrativa, outras fontes de informação como dados de fronteira, de empresas aéreas, fluxos de e-mails e mensagens eletrônicas podem ampliar nosso conhecimento de novas formas de mobilidade espacial.

A próxima seção traz a discussão conceitual feita até aqui no que se refere aos dados propriamente ditos.

\section{Alternativas}

As informações provenientes de registros administrativos sobre migrantes internacionais têm sido cada vez mais utilizadas como fontes de dados para estudos sobre migração. Embora não tenham a abrangência e detalhamento da investigação dos censos demográficos, têm como vantagem principal sua maior periodicidade, visto que são produzidas continuamente, ano a ano, e não apenas realizadas em datas específicas como os censos, geralmente com intervalo de 5 ou io anos.

Exemplos de registros cuja análise agregada tem-se intensificado nos últimos anos no Brasil são a Relação Anual de Informações Sociais (RAIS) e os dados do Sistema Nacional de Cadastramento de Registro de Estrangeiros (SINCRE) da Polícia Federal.

Nessas bases de dados, o conceito de migrante ou morador no território nacional é significativamente diferente do usado em censos e pesquisas domiciliares. Imigrantes 
constantes nessas fontes de informação, ainda que inseridos no mercado de trabalho formal, podem ter uma condição de permanência indefinida no país e, desse modo, não seriam considerados, segundo os censos demográficos, como imigrantes.

Outra diferença importante existente entre censos e registros é que os primeiros têm o propósito de produzir informações agregadas sobre temas de importância generalizada. Por outro lado, registros são obtidos de instituições cuja missão normalmente não é produzir informações agregadas, mas, sim, coletar dados individuais.

Um desafio que está proposto hoje, com o aumento do uso de registros administrativos para estudos de migração, é saber qual é a abrangência e cobertura de cada tipo de informação, qual o nível de interseção entre elas e quais os eventos que nenhuma delas consegue captar. Uma tentativa de avançar nessa questão seria tentar parear ou compatibilizar as diferentes bases de dados, o que ainda não está consolidado no Brasil.

A título de exemplificação, faremos um breve confronto dos resultados do Censo Demográfico 2010 com os dados do SINCRE, para o mesmo período. Esses registros são gerados no momento em que o estrangeiro faz a solicitação da carteira de estrangeiro e, desse modo, representam uma exigência legal para que os indivíduos estejam devidamente registrados no Brasil e possam exercer direitos reservados aos estrangeiros como, por exemplo, adquirir um visto de trabalho. Os registros do SINCRE apresentam informações de migrantes "documentados" ou que estão formalmente registrados no Brasil. São disponibilizadas informações sobre classificação do registro (permanente, temporário, provisório, fronteiriço), sexo, país de nascimento, estado civil, profissão, município e unidade da federação de residência, unidade da federação de entrada, meio de transporte, cidade de nascimento, idade e amparo legal do registro.

Contudo, como limitação, esse tipo de informação apenas cobre os indivíduos formalmente registrados e aqueles que buscam realizar o registro para algum fim específico, como obter vínculo formal de trabalho ou matrícula em instituição de ensino. Estrangeiros que residem no país mas que não buscam fazer o registro ou não são levados a efetivá-lo não constam na referida base de dados.

Foi feita uma comparação das informações dos estrangeiros constantes no SINCRE entre 2000 e 2010 com os dados dos estrangeiros captados pelo Censo Demográfico que fixaram residência no Brasil no mesmo período. As variáveis utilizadas para a comparação foram sexo, idade, estado civil, unidade da federação de residência e país de nascimento. 
O total de estrangeiros que chegaram ao país ou que aqui se registraram na década de 2000 , captado por cada fonte de informação é bastante parecido. Se no Censo foram enumerados I8I mil estrangeiros, nos registros do SINCRE contabilizaram-se I9I mil registros. Contudo, apesar de próximos, uma análise detalhada dos dados atesta que eles se referem a indivíduos distintos. O Censo captou um número maior de mulheres do que o SINCRE, cujos registros são compostos de 65\% de homens, em comparação aos $57 \%$ captados pelo Censo. Isso faz com que a proporção entre homens e mulheres (razão de sexo) dos registros do SINCRE atinja o valor de I,9, enquanto a do Censo é de I,32.

A análise da composição dos estrangeiros segundo os grupos de idade também mostra diferenças significativas entre os registros das duas fontes. A estrutura etária dos estrangeiros registrados pelo SINCRE estava fortemente concentrada nas idades adultas, tipicamente ligadas ao mercado de trabalho, sendo ligeiramente mais envelhecida para os homens. Há uma ausência de crianças e jovens nos registros do SINCRE e uma participação maior de idosos em relação à população captada pelo Censo. A estrutura etária dos estrangeiros registrada pelo Censo apresenta um aspecto mais próximo de uma pirâmide etária populacional típica, com presença de adultos e crianças, embora haja relativamente poucos jovens com idade entre I5 e 20 anos. Em suma, a estrutura etária captada pelo Censo aproxima-se daquela que seria apresentada por um tipo de "migração familiar", enquanto os registros do SINCRE aproximam-se de uma “migração individual”.

A análise do estado civil, entretanto, indica que o percentual de casados é maior nos registros do SINCRE em comparação com os dados do Censo, embora apenas com base nessa informação não tenhamos como determinar sobre o estado conjugal do estrangeiro - se ele vive ou não em companhia de companheiro -, mas apenas seu estado civil ou situação jurídica.

Em ambas as fontes, a Bolívia representa o principal país de origem de estrangeiros residentes no país, atingindo $20 \%$ dos registros do SINCRE e 15\% do Censo. Também merecem destaque os naturais do Paraguai, da Argentina, dos Estados Unidos, do Peru e de Portugal.

Há diferença entre a captação por país de nascimento entre as fontes. O Censo tem uma captação relativamente superior à do SINCRE no que se refere a estrangeiros oriundos dos países que são tradicionais destinos de migração internacional de brasileiros, como os Estados Unidos, o Japão, o Reino Unido e a Espanha, além de países 
vizinhos como o Paraguai, Uruguai e a Colômbia. Quanto ao registro de indivíduos nascidos na China, no Líbano e na Coreia do Sul, Itália e Alemanha, o SINCRE apresenta uma maior captação em comparação ao Censo.

A análise do local de residência dos estrangeiros mostra uma concentração mais elevada dos registrados no SINCRE nos principais centros econômicos do país, como São Paulo e Rio de Janeiro. Por outro lado, os estrangeiros captados pelo Censo residem em maior proporção em estados que são regiões de emigração de brasileiros para o exterior, como Minas Gerais, Paraná e Goiás.

As análises realizadas demonstram que, embora o contingente de estrangeiros registrados pelas duas fontes aproxime-se numericamente, as diferenças no conceito de migrante presentes em cada uma delas fazem com que captem indivíduos diferentes. Enquanto os estrangeiros captados pelo Censo apresentam uma estrutura tipicamente "familiar", formada por adultos e crianças, com uma proporção relativamente equilibrada entre homens e mulheres, os dados do SINCRE referem-se a indivíduos adultos, com predominância de homens, residentes nas principais regiões econômicas do país. Por outro lado, a distribuição espacial dos estrangeiros captados pelo Censo é mais diluída no território, principalmente entre unidades da federação que são regiões de origem de brasileiros que migram para o exterior. Nesse sentido, vê-se também que, no Censo, há uma maior concentração de estrangeiros oriundos de países que são tradicionais destinos de emigração de brasileiros do que nos dados do SINCRE.

O Censo Demográfico, por ser uma pesquisa de base domiciliar que exige o atendimento de critérios específicos para que estrangeiros sejam considerados residentes no Brasil gera bons registros de população com condição de residência “definitiva”, de caráter tipicamente familiar. Contudo, o Censo não registra indivíduos que têm sua situação de residência indefinida ou temporária, mas que aqui vivem. Por outro lado, os dados do SINCRE concentram-se entre os migrantes laborais, incluindo aqueles com condição indefinida de permanência no país, e não registrem estrangeiros que não buscam o sistema para a realização do registro, como crianças e migrantes indocumentados. 


\section{Provocações}

Um desafio considerável que se impõe aos estudos de migração e mobilidade espacial da população é produzir informações que acompanhem fluxos cada vez mais dinâmicos e complexos. Isso intensificou o uso dos registros administrativos e, conforme destacado na seção anterior, expôs os alcances e as limitações das fontes de dados "tradicionais" como os censos demográficos, em grande parte centradas em questões de natureza conceitual. Paralelamente, os registros de população têm sido submetidos ao mesmo tipo de escrutínio que os censos sofreram há alguns anos. Com isso, podese perceber que mesmo sendo mais “ágeis” e atualizados que os dados censitários, não conseguem acompanhar as mudanças nos padrões de mobilidade experienciados no início do presente século.

Uma das "novidades" metodológicas recentes nos estudos de população é a utilização de bases de dados virtuais como fonte de informação. São informações oriundas de fontes diversas, como dados da internet, dos sistemas de telefonia e comércio, redes sociais digitais, acesso a sites, chamadas telefônicas, mensagens eletrônicas, servidores de e-mail, operadoras de cartão de crédito, entre outros. Essas grandes bases de dados ("big data”) entraram recentemente na lista de fontes dos estudos da dinâmica populacional. Exemplos disso são a criação de um grupo de trabalho global sobre big data na divisão de estatística das nações unidas (http://unstats.un.org/bigdata/), o painel científico da União Internacional para o Estudo Científico de População (IUSSP) sobre Big Data and Population Processes (http://iussp.org/en/panel/big-data-andpopulation-processes) e a presença de oficinas de trabalho e de uma mesa redonda sobre Web and Social Media for Demographic Research no congresso conjunto da Associação Latinoamericana de População (ALAP) (http://I87.45.I87.I30/ abeporgb/ xxencontro/index.php/).

No caso da migração, estudos recentes têm utilizado, por exemplo, dados do Twiter (ZAGHENI et al., 20I4) de contas de e-mail (STATE, WEBER\&ZAGHENI, 20I3), uso de celular (SUST et al. 20I4) e de ferramentas de pesquisa na internet (UN GLOBAL PULSE,20I4).

O interesse e a facilidade de uso desse tipo de informação, ampliado ainda pelo seu grau de novidade e também - importante destacar - pelo baixo custo de produção, 
põe em questão os agenciamentos e instituições tradicionais de provimento de informações sobre migração, dando indícios das direções que a produção de informações sobre o tema toma(rá) nos momentos históricos atual e futuro.

A heterogeneidade presente nessas fontes de dados possivelmente provocarão uma nova recategorização sobre o que deve ser considerado como migração e quais outras formas de mobilidade espacial devem ser pesquisadas. Como ocorreu no caso dos registros administrativos, em que tivemos de repensar os conceitos utilizados nas fontes tradicionais e os alcances e limites dessas bases de dados, novamente precisaremos discutir quais tipos de informações as novas bases fornecerão de forma confiável para estudos de migração.

Novamente, uma tensão conceitual surge com novos dados, expondo formas de mobilidade e migração que até então não enxergávamos, assim como contornos do que, no passado recente, pensávamos ser a totalidade passível de ser mensurada de forma quantitativa em termos de migração internacional. Qualquer tentativa de fuga da problematização conceitual dos processos de produção de informação sobre migração pode deixar-nos ainda mais defasados em termos de mensuração dos fluxos populacionais contemporâneos. 


\section{Referências}

ANDERSON, B. Imagined Communities: reflections on the Origin and Spread of Nationalism. London and New York: Verso Books, I99I.

COURGEAU, D. Méthodes de Mesure de la mobilité spatiale: migrations internes, mobilité temporaire, navettes. Éditions de L'Institut National d'Etudes Démographiques. Paris: L'institut national d'études démographiques, I988.

CRESSWELL, T. On the Move: mobility in the modern western world. London: Routledge, 2006.

DESROSIÈRES, A. La política de los grandes números: historia de la razón estadística.

Barcelona:Melusina, 2004 .

POLÍTICA FEDERAL - DPF. Sistema Nacional de Cadastramento de Registro de Estrangeiros. Coordenação Geral de Polícia de Imigração.

FOUCAULT, M. Microfísica do Poder. Rio de Janeiro: Graal, I979.

FOUCAULT, M. Vigiar e Punir. Petrópolis: Vozes, I975.

IBGE. Microdados da Amostra do Censo demográfico 2010. Rio de Janeiro: IBGE, $20 \mathrm{Io.}$

IGO, S. E. The Averaged American: surveys, Citizens, and the Making of a Mass Public.

Cambridge:Harvard University Press, 2008.

LATOUR, B. A esperança de Pandora: ensaios sobre a realidade dos estudos científicos. Bauru: EDUSC, 200I.

LÉVY, P. O que é o virtual? Rio de Janeiro: Ed. 34, 1996.

PORTER, T. Trust in Numbers: the Pursuit of Objectivity in Science and Public Life. Princeton:Princeton University Press, I995.

RAVENSTEIN, E. The laws of migration. Journal of the Royal Statistical Society. Series A (Statistics in Society), London, v. 52, n. 2, p. 24I-305, Jun. 1889.

STATE, B; WEBER, I; ZAGHENI, E. Studying inter-national mobility through ip geolocation. In: ACM. Proceedings of the sixth ACM international conference on Web search and data mining. 20I3. 
SUST, V. Big Data and Tourism: new indicators for tourism management. Barcelona: RocaSalvatella and Telefonica, 20I4.

UN Global Pulse. Estimating migration flows using online search data. Global Pulse Project Series, n. 4,2014 .

ZAGHENI, E et al. Inferring international and internal migration patterns from twitter data. In: ACM. Proceedings of the 23rd International Conference on World Wide Web. [S.1.], 2014. 